BBA 75474

\title{
NONEQUILIBRIUM FACILITATED DIFFUSION OF OXYGEN THROUGH MEMBRANES OF AQUEOUS COBALTODIHISTIDINE
}

ROBERT J. BASSETT * AND JEROME S. SCHULTZ

Division of Chemical Engineering, The University of Michigan, Ann Arbor, Mich. 48104 (U.S.A.)

(Received February 27th, 1970)

SUMMARY

I. The reversible reaction of oxygen with cobaltodihistidine to form oxy-bis(cobaltodihistidine) in aqueous solutions was used as a model system to study the characteristics of facilitated diffusion in membranes. The cobaltodihistidine molecule served as the model carrier species, and the unequal diffusivities of the two carrier forms as well as a two-step reaction mechanism added a degree of complexity not treated in previous studies.

2. Facilitation of the oxygen flux through the membrane increased with oxygen gradients but also showed saturation effects at high oxygen partial pressures. Facilitation was proportional to (membrane thickness) ${ }^{-\mathbf{0 . 2 2}}$ in the range of $5^{0-280} \mu$, and to total carrier concentration up to $0.030 \mathrm{M}$ cobaltodihistidine. There was no further increase in facilitation at higher carrier concentration because of the solubility limit for cobaltodihistidine. Facilitation increased with temperature and showed an apparent activation energy of $4.44 \mathrm{kcal} / \mathrm{mole}$. Maximum facilitation was found in a $\mathrm{pH}$ region near neutrality.

3. The facilitated fluxes were about one-third of the magnitude predicted by a simple model which assumes chemical equilibrium throughout the film but could be accurately predicted by a complete model which allows for a finite reaction rate within the membrane. The correct equations and boundary conditions for both the equilibrium and nonequilibrium models are delineated, as well as numerical techniques for obtaining solutions. The total carrier concentration, free plus complexed, is not necessarily uniform throughout each position in the membrane, but the integrated carrier concentration profile across the membrane is a constant.

\section{INTRODUCTION}

In order to explain the transport kinetics and specificity of biological membranes, the carrier hypothesis has often been invoked ${ }^{1,2}$. The mechanism by which carrier species facilitate the transport of specific permeants across biological membranes has not been elucidated. However, one mechanism often discussed either implicitly ${ }^{2}$ or explicitly ${ }^{3}$ is the movement of carrier and carrier-permeant complexes

\footnotetext{
${ }^{\star}$ Present address: E. I. DuPont de Nemours, Wilmington, Del., U.S.A.
} 
across membranes by simple molecular diffusion. The characteristics of such a mechanism has not been completely analyzed, either experimentally or theoretically, and the main thrust of this work is to present a comprehensive study of a model facilitated transport system so as to clarify the understanding of the diffusive model for carrier transport across membranes. WYMAN ${ }^{4}$ has delineated the difference between the equilibrium and nonequilibrium models for facilitated diffusion but did not provide a method for solving the equations. LAFORCE ${ }^{5}$ attempted a solution of the nonequilibrium diffusion equations but was unsuccessful because of instabilities in the numerical computer method used. KUTCHAI et al. ${ }^{6}$ obtained a solution to the nonequilibrium diffusion equations for facilitated oxygen transport in hemoglobin with a numerical quasi-linearization technique.

Of the model aqueous phase facilitated transport systems which have been investigated experimentally, the most common are the hemoglobin-oxygen system and the bicarbonate-carbon dioxide system. Several workers have verified the role of the hemoglobin molecule in the facilitation of the steady state diffusion of oxygen in aqueous solution ${ }^{7-13}$. In this case, the carrier molecule, hemoglobin, combines reversibly with molecular oxygen in a water film and provides an additional diffusive transport mechanism which is specific for oxygen. Under certain experimental conditions, while the diffusion of nitrogen through an aqueous layer of hemoglobin was by simple diffusion, that is in proportion to the applied pressure difference, the observed oxygen flux was as much as 8 times larger than predicted by simple diffusion of oxygen through a comparable water film ${ }^{11}$. In the bicarbonate-carbon dioxide system, several workers found a similar positive effect, with the presence of added bicarbonate ion facilitating the diffusion of carbon dioxide ${ }^{\mathbf{1 4}}$. Other investigators established the effect of the enzyme carbonic anhydrase as a specific carrier molecule and also in conjunction with the bicarbonate ion ${ }^{15,16}$. Both carrier mechanisms contribute to the facilitated diffusion of carbon dioxide in thin aqueous films and the combined effect can increase the permeability of carbon dioxide by as much as an order of magnitude ${ }^{15}$.

Based on these experimental findings, the aim of this work was to simulate and to characterize completely a facilitated transport system so that the mechanism for facilitated transport could be unequivocally evaluated. Thus, an important part of the experimental study was to select a suitable carrier molecule for the proposed model membrane and to investigate the effects of various system parameters such as temperature, solution $\mathrm{pH}$, diffusion path length and carrier concentration on the magnitude of the facilitation component of the total flux. Such a specific carrier molecule for oxygen is the amino acid chelate of the cobaltous ion, cobaltodihistidine, and the experimental part of this work is concerned with the effect of this carrier molecule on the steady-state diffusion of oxygen in thin aqueous films ${ }^{17}$.

STEIN $^{12}$ has also performed some experimental studies with the cobaltodihistidine-oxygen system, but his experiments were carried out with relatively thick films $(0.33 \mathrm{~cm})$ and therefore were restricted to the "equilibrium region" a special case of facilitated transport.

\section{Reversible reaction of oxygen with cobaltodihistidine}

The equilibrium reaction of cobaltodihistidine and molecular oxygen in the aqueous phase has been studied in great detail by HEARON et al. ${ }^{18}$ and their results 
confirmed by Simplicio AND WiLkins ${ }^{19}$. They showed that the carrier molecule, cobaltodihistidine, is formed from the following chemical equilibria:

$$
\begin{aligned}
& 2 \phi \mathrm{H} \leftrightarrows 2 \phi^{-}+2 \mathrm{H}^{+} \\
& 2 \phi^{-}+\mathrm{Co}^{2+} \leftrightarrows \mathrm{Co}_{2}
\end{aligned}
$$

where $\phi \mathrm{H}$ represents the neutral histidine molecule and $\phi^{-}$the histidine anion.

The overall equilibrium constant $\left(K_{1}\right)$ for the chelation of cobalt by histidine is given by

$$
K_{1}=\frac{\left[\mathrm{Co} \phi_{2}\right]\left[\mathrm{H}^{+}\right]^{2}}{[\phi \mathrm{H}]^{2}\left[\mathrm{Co}^{2+}\right]}=2.09 \cdot 10^{-7} \text { at } 25^{\circ}
$$

and a simple calculation shows that reaction is essentially complete when the $\mathrm{pH}$ of the solution is above 7.0.

In cobaltodihistidine, proposed conformation ${ }^{18}$ shown below, all bonding sites in the histidine structure are coordinated to the cobalt atom in both the solid state ${ }^{20}$ and in aqueous solution ${ }^{21}$. It has been shown that the imidazole groups of the histidine structures are in a trans configuration to one another in the crystal structure ${ }^{20}$ and that, if this favorable arrangement persists in a water solution of cobaltodihistidine, the carboxylate groups must be cis to one another due simply to the enantiomeric conformation of the ligand ${ }^{22}$.

The presence of oxygen in a water solution of cobaltodihistidine produces a visible color change in the solution. An anaerobic solution if sufficiently dilute is practically colorless; if more concentrated, it is slightly pink; but when oxygenated, the solution color becomes deep amber. The color change may be reversed by flushing the solution with nitrogen or hydrogen and the cycle may be repeated essentially indefinitely ${ }^{18}$. Further, if a solution of histidine and cobaltous ion is placed in an atmosphere of nitrogen at a $\mathrm{pH}$ value such that the cobalt is incompletely bound, the solution $\mathrm{pH}$ is observed to fall when the solution is oxygenated ${ }^{18}$. This fall in $\mathrm{pH}$ is reversible with oxygen pressure and may be completely abolished by returning the system to an atmosphere of nitrogen and this cycle may be repeated many times. All these effects have been quantitatively described by the following chemical equilibria:

$$
\begin{aligned}
& 4 \phi \mathrm{H}+2 \mathrm{Co}^{2+} \leftrightarrows 2 \phi_{2} \mathrm{Co}+{ }_{4} \mathrm{H}^{+} \\
& 2 \phi_{2} \mathrm{Co}+\mathrm{O}_{2} \leftrightarrows\left(\phi_{2} \mathrm{Co}\right)_{2} \mathrm{O}_{2}
\end{aligned}
$$

Diagramatically the proposed structures in the oxygenation step are shown on the next page ( $c f$. ref. I 8 ). The effect of temperature on the equilibrium constant for the oxygenation reaction (D) was also determined by HEARON et al. ${ }^{18}$.

$$
\log _{\mathrm{e}} K_{2}=\left(\frac{19000}{T}-4^{8.5}\right)^{1^{2} \cdot \mathrm{mole}^{-2}}
$$

Both cobaltodihistidine and the reversible product, oxy-bis(cobaltodihistidine), have been quantitatively isolated and identified as those chemical forms predicted by the proposed equilibria ${ }^{22}$. The reversible product, oxy-bis(cobaltodihistidine), has been shown to be diamagnetic ${ }^{18,21,23}$ with a cobalt: histidine: oxygen ratio of $2: 4:$ I and to be a binuclear species with an ester linkage joining the two cobaltodihistidine residues ${ }^{22}$. In this binuclear peroxy species, one carboxylate group has been severed from each cobalt atom to allow the formation of the peroxy bridge. Further 


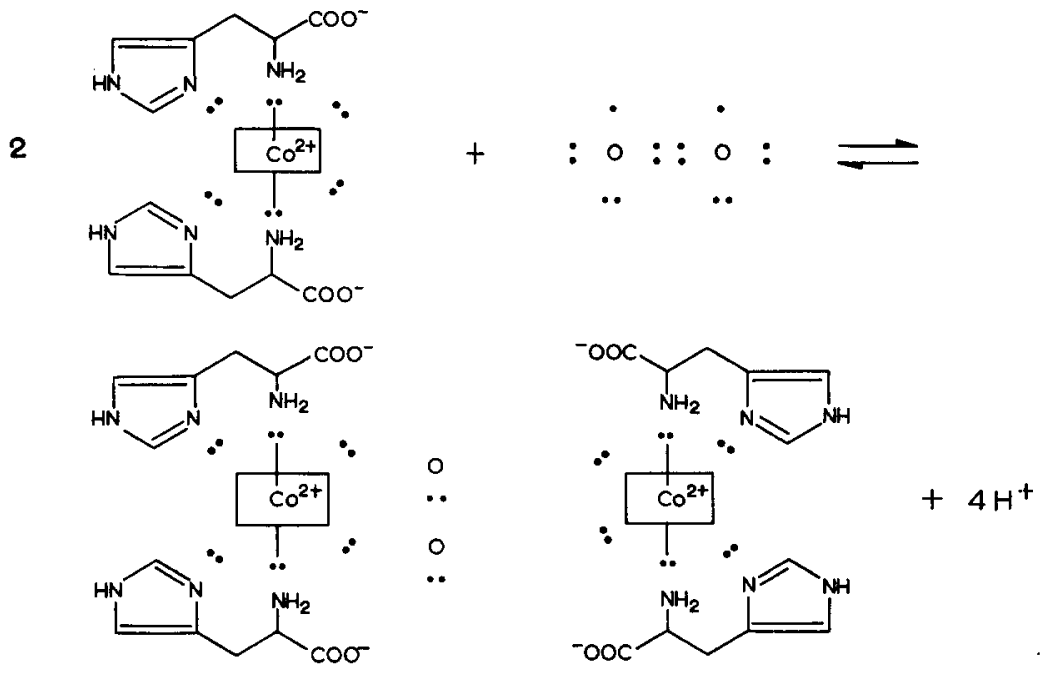

studies revealed that a neutral or slightly acidic solution was required to eliminate the formation of carbon dioxide which always occurs in an alkaline solution of histidine ${ }^{18}$. Thus, an optimal solution $\mathrm{pH}$ of 7.0 was chosen for this experimental study both to maximize the formation of the chelate, cobaltodihistidine, and to eliminate the possible breakdown of the histidine structure by the presence of excess hydroxyl ion in the solution.

The presence of the irreversible complex in an aqueous solution of cobaltodihistidine is easily detected since it produces a specific optical spectrum unlike that of either of the reversible complexes ${ }^{18}$. HEARON and co workers first postulated the existence of the irreversible product and concluded that 1.5 moles of cobaltous ion are consumed in the formation of one mole of the irreversible complex which apparently did not contain any cobaltic ions. More recent studies indicate that the irreversible complex involves the addition of a molecule of oxygen to the reversible complex, oxy-bis(cobaltodihistidine), with the subsequent oxidation of the cobaltous ion to the plus three state 22,24 . In solutions with $4.84 \cdot \mathrm{IO}^{-3} \mathrm{M}$ cobaltous ion and a $2: \mathrm{I}$ histidine to cobalt ratio, I.I4 moles of oxygen are consumed per mole of oxy-bis(cobaltodihistidine) used in the formation of the irreversible product. At higher histidine: cobalt ratios, greater amounts of oxygen are consumed (e.g. $1.32 \mathrm{moles} / \mathrm{mole}$ of oxy-bis(cobaltodihistidine) at a $4:$ I ratio) ${ }^{25}$. The presence of traces of unidentifiable organic residues after the reaction was complete suggests that some of the oxygen, probably that in excess of I:I per mole of oxy-bis(cobaltodihistidine), is used in the oxidation of histidine, as has been suggested by BECK $^{26}$ and others ${ }^{27}$. SimpLicio AND WILKINS $^{19}$ determined the kinetic mechanism of the reaction of cobaltodihistidine and molecular oxygen in water. In this study, the kinetics of the formation and decomposition of oxy-bis(cobaltodihistidine) were investigated spectrophotometrically in a modified stopped-flow apparatus. The kinetic data obtained supported the following two-step mechanism:

$$
\begin{aligned}
& \mathrm{Co} \phi_{2}+\mathrm{O}_{2} \underset{k-1}{\stackrel{k_{1}}{\rightleftarrows}}\left(\mathrm{CO}_{2}\right) \mathrm{O}_{2} \\
& \left(\mathrm{Co} \phi_{2}\right) \mathrm{O}_{2}+\mathrm{CO} \phi_{2} \underset{k_{2}^{-}}{\stackrel{k_{2}}{\rightleftarrows}}\left(\mathrm{Co} \phi_{2}\right)_{2} \mathrm{O}_{2}
\end{aligned}
$$


From the experimental results ${ }^{19}$,

$$
\begin{aligned}
& k_{1}=5.0 \cdot 10^{7} \exp (-5600 / R T) 1 \cdot \mathrm{mole}^{-1} \cdot \mathrm{sec}^{-1} \\
& k_{-2}=6.0 \cdot 10^{17} \exp (-26000 / R T) \mathrm{sec}^{-1}
\end{aligned}
$$

\section{MATERIALS AND METHODS}

\section{Continuous flow system for flux measurements}

Several variables affect the degree of facilitation realized in carrier-mediated transport systems. The most important system parameters are: (r) gas partial pressure gradient; (2) diffusion path length; (3) carrier concentration; (4) temperature; (5) solution $\mathrm{pH}$.

The primary requirements of the experimental program were met by supporting thin liquid films of the cobaltodihistidine carrier solution on membrane filters and then accurately measuring each of the small gas fluxes across the membrane.

Stock solutions of L-histidine and cobaltous chloride were prepared from reagent grade L-histidine (Nutritional Biochemical Corp.) and cobaltous chloride (Allied Chemical Corp.); the stock solutions of histidine were stored at $6^{\circ}$ where it was possible to store them for extended periods of time without any noticeable degradation. Stoichiometric amounts of the two stock solutions were then used to form the test solutions of cobaltodihistidine, and the $\mathrm{pH}$ adjusted. Since the irreversible reaction of oxy-bis(cobaltodihistidine) and oxygen was observed to take place within a day even when stored at $6^{\circ}$, the cobaltodihistidine test solutions were prepared "fresh" before each experimental run. After the liquid was allowed to soak up through the membrane, excess surface liquid was blotted from the membrane and the membrane was placed in the diffusion cell.

A schematic diagram of the continuous flow system modified after WiTTENBERG ${ }^{13}$ is depicted in Fig. I. Gas mixtures of known composition are circulated past each side of a membrane (Gelman Instrument Co., Type GA-6) charged with the test solution and mounted in a diffusion cell made of Lucite. In this and subsequent discussions, the high oxygen concentration side of the membrane is considered the upstream chamber. A detailed drawing of the diffusion cell is shown in Fig. 2. The gas

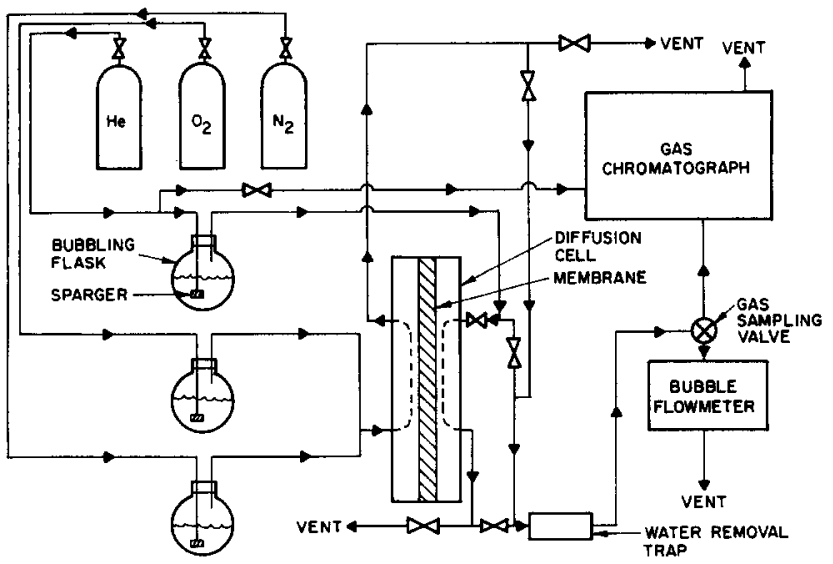

Fig. 1. Flow system for flux measurements.

Biochim. Biophys. Acta, 2 I I (I970) I94-2 I5 
stream entering each chamber passes through one major inlet port and then through three symmetric channels to the gas chamber. The gas stream then leaves the gas chamber through a similar system of channels to the major outlet port. This design ensures a well-mixed gas volume in each chamber so that the measured composition of the existing gas determines the driving forces for mass transfer across the membrane.

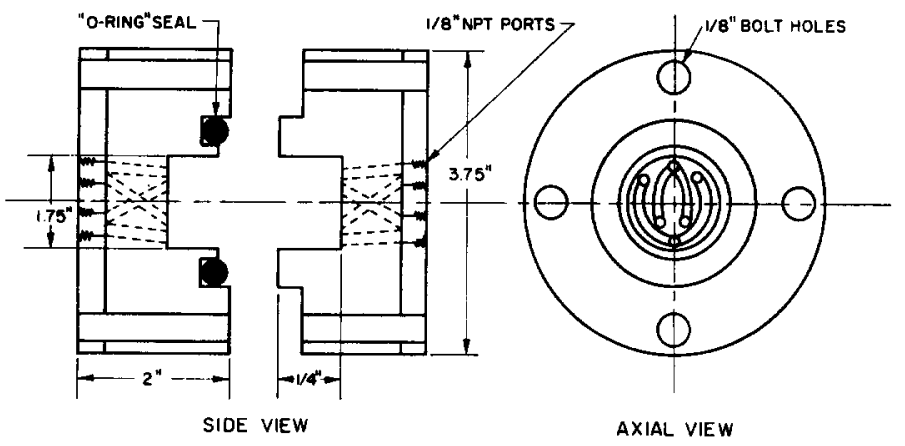

Fig. 2. Flow system diffusion cell.

Each chamber volume is $8.64 \mathrm{~cm}^{3}$ and the exposed area of the membrane is I5.5 $\mathrm{cm}^{2}$. The upstream and downstream flow rates are adjusted so that pressure drops in the system are negligible and the total gas pressure on either side of the membrane is I atm. This prevents any physical flexing of the membrane, a fact which was verified visually since the Lucite diffusion cell is transparent. The flow method allows one to study a wide range of partial pressure driving forces for mass transfer while maintaining no physical pressure drop across the membrane.

The upstream gas consisted of a mixture of oxygen and nitrogen at a flow rate of $20-40 \mathrm{~cm}^{3} / \mathrm{min}$, while the inlet gas stream of the downstream chamber consisted of pure helium at a flow rate of $\mathrm{I}-20 \mathrm{~cm}^{3} / \mathrm{min}$. The inlet helium stream then swept out any gas which diffused across the liquid film and the effluent downstream gas mixture was then analyzed for oxygen and nitrogen by passing a portion of the gas mixture through a gas chromatograph.

The measurement of nitrogen fluxes was undertaken to provide an internal standard for the experimental procedure. Any leaks in the system immediately altered the nitrogen flux which then led to corrective action. The nitrogen flux did not change with different carrier concentrations, indicating no substantial change in gas solubility or diffusivity over the range of solute concentrations employed.

The system variables investigated were carrier concentration, temperature, solution $\mathrm{pH}$ and the diffusional path length. In the diffusional path length studies, path lengths of approx. $5^{\circ}$ and $75 \mu$ were investigated by constructing a "sandwich" of membranes each with a thickness of approx. $25 \mu$ (Millipore Filter Corp., Type HA45). The "sandwich" structure was cemented to polystyrene annular rings by applying a polystyrene-toluene mixture to the outer rim of the membrane "sandwich" and pressing the annular rings on either side of the "sandwich". The exposed area of the membrane structure was $13.4 \mathrm{~cm}^{2}$. The resultant membrane unit was then placed directly into the flow system diffusion cell. Path length studies at $280 \mu$ were conducted by placing two $140-\mu$-thick membranes in a "sandwich" structure and placing them 
in the flow system diffusion cell. No annular ring support structure was necessary in this case since the membranes were sufficiently thick to ensure no breakage when subjected to the support stresses of the diffusion cell.

\section{RESULTS AND DISCUSSION}

\section{Effect of concentration gradient}

At a given temperature, with the membrane charged with a solution of cobaltodihistidine, the nitrogen flux was found to follow Fick's law (i.e. linear with concentration gradient) while the observed oxygen flux was increased above the value obtained through a comparable water film. The results of typical studies are indicated in Figs. 3, 4 and 5. The magnitude of the facilitated component, that is the difference between the measured total oxygen flux and the flux that would be obtained in the absence of carrier, was found to be constant over a wide range of upstream oxygen pressures and increased with temperature. The results seem reasonable in view of the fact that shapes of the saturation curves for cobaltodihistidine and oxygen (Fig. 6) show that the carrier becomes saturated above oxygen pressures of $\mathrm{I} 5$ inches $\mathrm{Hg}$.
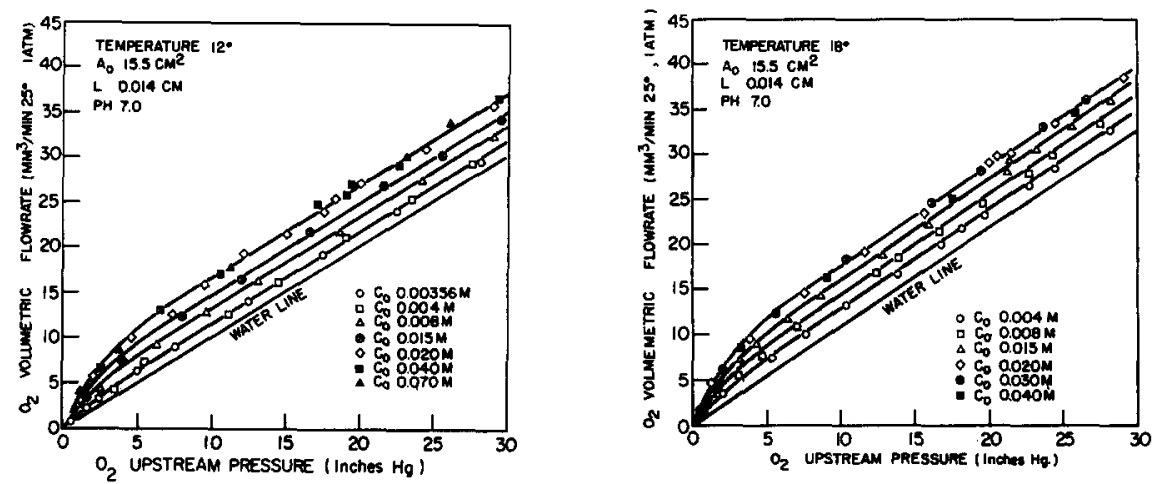

Fig. 3. Effect of carrier concentration on oxygen diffusion at $12^{\circ}$.

Fig. 4. Effect of carrier concentration on oxygen diffusion at $18^{\circ}$.
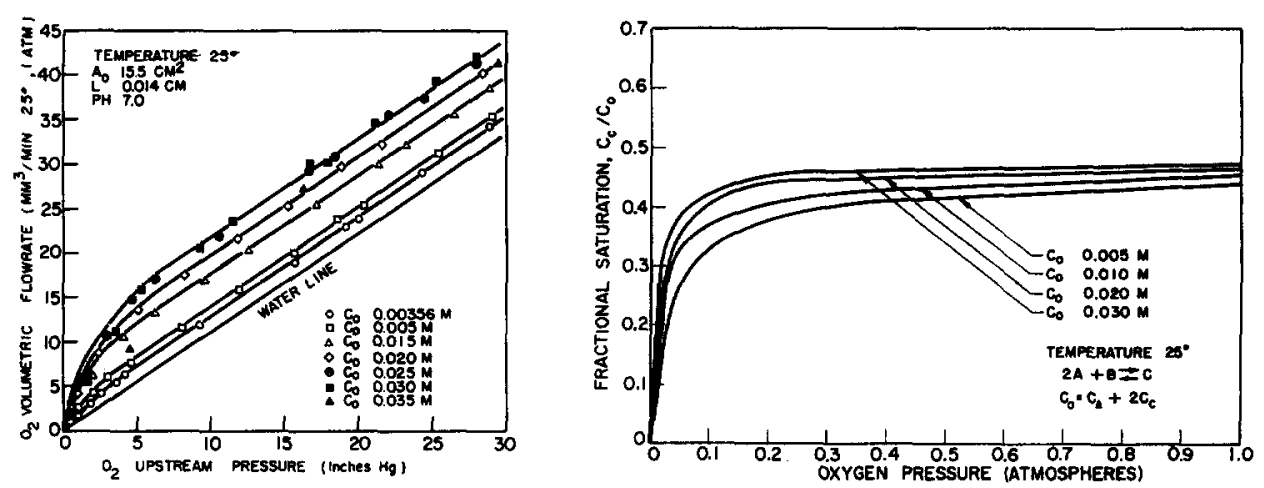

Fig. 5. Effect of carrier concentration on oxygen diffusion at $25^{\circ}$.

Fig. 6. Cobaltodihistidine-oxygen saturation curves. 
At $12^{\circ}$ and $18^{\circ}$, Figs. 3 and 4 show that the facilitation was constant for upstream oxygen pressures greater than about ro inches $\mathrm{Hg}$ and the observed oxygen flux lines were parallel to the water flux line for oxygen. However, at $25^{\circ}$, the observed oxygen flux line was not exactly parallel to the water line and indicated that the facilitation component decreased by about $3 \%$ of the highest oxygen pressures. Extended time studies showed irreversible carrier reactions were negligible at $25^{\circ}$. However, at $30^{\circ}$ an irreversible reaction of the carrier did occur to a significant extent.

\section{Effect of diffusion path length}

The effect of diffusional path length on the facilitated transport of oxygen was investigated at $25^{\circ}$ and with a total carrier concentration $C_{0}=0.03 \mathrm{M}$. Membranes with different thicknesses from 50 to $280 \mu$ were prepared as described above. The observed nitrogen flux, in each case, provided an internal standard and allowed the calculation of the equivalent path length of each membrane structure. The magnitude of the observed facilitation varied inversely with the diffusion path length at a given setting of the upstream oxygen pressure. A log-log plot of the variables is presented in Fig. 7. The magnitude of the facilitation effect is shown in the analysis section to be given by

$$
\frac{D_{\mathrm{C}} \Delta C_{\mathrm{C}}}{L}
$$

where $D_{\mathrm{C}}$ is the aqueous diffusion coefficient of oxy-bis (cobaltodihistidine); $\Delta C_{\mathrm{C}}$ is the overall concentration gradient of oxy-bis (cobaltodihistidine); $L$ is the effective diffusion path length.

If $\Delta C_{\mathrm{C}}$ is constant and independent of path length as is the case in a carrier system at chemical equilibrium ${ }^{\mathbf{2 8}}$, then the magnitude of the facilitation should vary inversely with path length and a $\log -\log$ plot of the variables should have a slope of $-\mathrm{I}$. The best line through the data indicates a slope of -0.92 which is close enough to - I so that one might conclude that the reaction is at equilibrium. But, detailed calculations show that this system is in fact very far from equilibrium, indicating that inverse proportionality of the flux with length is not a good criterion concerning the nature of the speed of the chemical reaction.

\section{Effect of carrier concentration}

At a given temperature, as $C_{0}$, the total concentration of carrier originally added to the system, increased, the observed magnitude of the facilitation of the oxygen transport increased. An example of this effect at $25^{\circ}$ is presented in Fig. 8. The relation between the variables was found to be linear at low values of $C_{0}$ with the magnitude of the facilitation effect approaching a constant value as the total carrier concentration was increased further. This behavior indicates that a physical limiting process is in effect as the carrier concentration increases and it was found that cobaltodihistidine reaches its solubility limit at about $0.03 \mathrm{M}$ at $25^{\circ}$. This effect was observed at each temperature and at each setting of the upstream oxygen pressure. Results for the experimental runs at $12^{\circ}, 18^{\circ}$ and $25^{\circ}$ are presented in Figs. 3, 4 and 5, respectively. In all cases, the facilitation was found to increase until a certain value $C_{0}$ was exceeded and then the oxygen flux curves remained fixed in shape and 
position. This limiting carrier concentration was increased with an increase in the system temperature, indicating that the solubility of the limiting carrier form increases with temperature.

Solubility studies were conducted on both the oxygenated and unoxygenated carrier forms at $25^{\circ}$. The results for oxy-bis(cobaltodihistidine) are presented in Fig. 9. No apparent solubility limit was observed in the region of $C_{0}=0.035 \mathrm{M}$ and thus it appears that no solubility limit exists for the oxygenated carrier form in the region of interest. However, it should be noted that brown needle-like crystals were observed in an oxygenated cobaltodihistidine solution at $C_{\mathbf{0}}=0.03 \mathrm{M}$ at $5^{\circ}$. All solutions of oxy-bis(cobaltodihistidine) appeared to obey Beer's law with a molar extinction coefficient of $5.23 \cdot \mathrm{xo}^{3} \mathrm{l} \cdot \mathrm{mole}^{-1} \cdot \mathrm{cm}^{-1}$ at $\lambda=385 \mathrm{~m} \mu$. This result is higher than the value of $\mathrm{I.62} \cdot \mathrm{IO}^{3} 1 \cdot \mathrm{mole}^{-1} \cdot \mathrm{cm}^{-1}$ reported by HEARON et al. ${ }^{18}$ and somewhat lower than the value of $7 . \mathrm{I} \cdot \mathrm{IO}^{\mathbf{3}} \mathrm{1} \cdot \mathrm{mole}^{-1} \cdot \mathrm{cm}^{-1}$ as reported by SIMPLICIO AND WILKINS ${ }^{19}$.
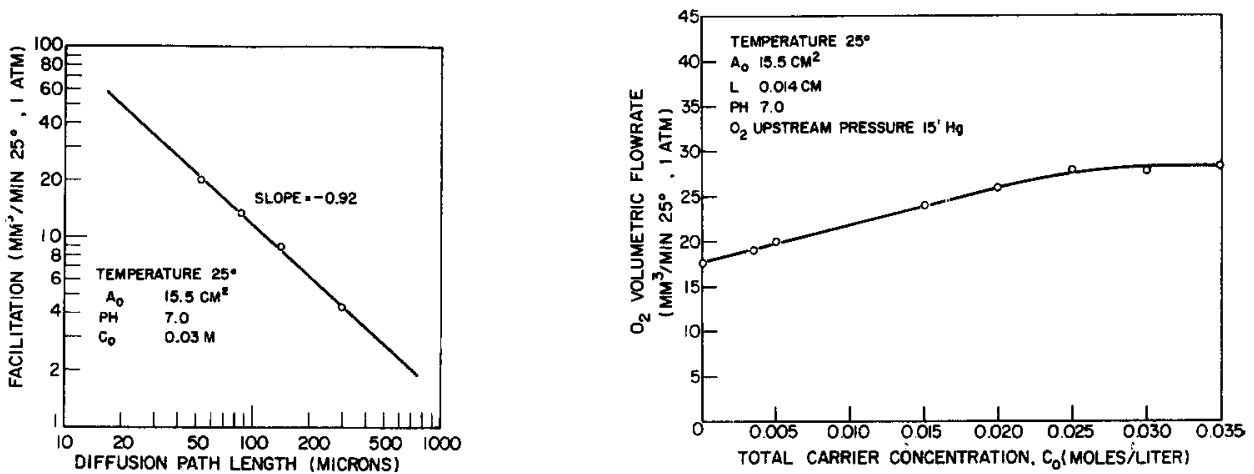

Fig. 7. Effect of membrane fluidness on facilitation.

Fig. 8. Effect of carrier concentration on oxygen transport.
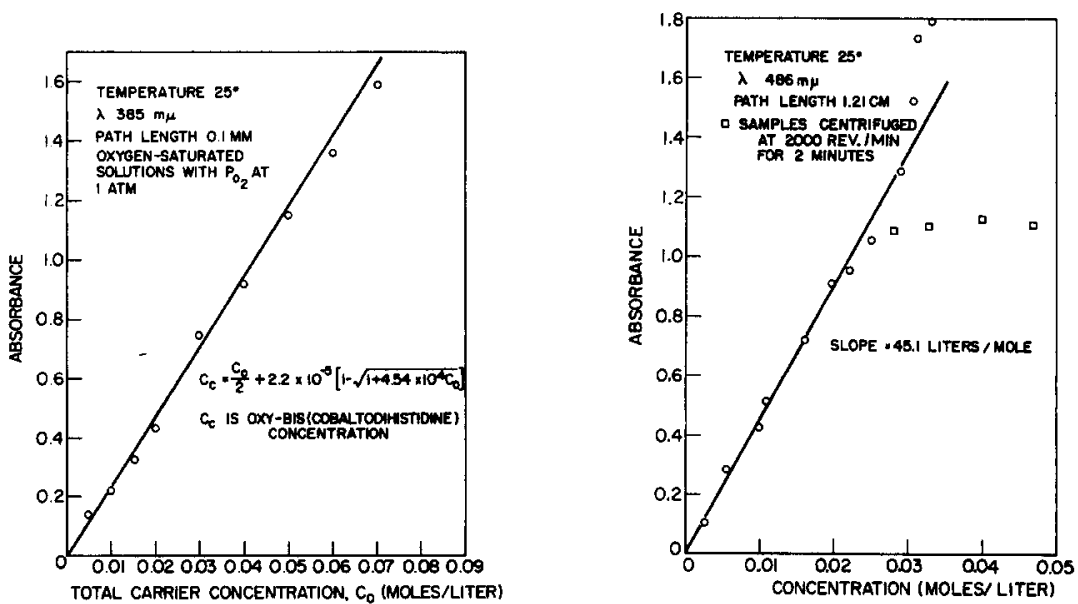

Fig. 9. Solubility study of oxy-bis(cobaltodihistidine).

Fig. Io. Solubility study of cobaltodihistidine.

Biochim. Biophys. Acta, 2 I I (1970) I94-2I5 
The results for the study of the unoxygenated carrier form are presented in Fig. Io. For concentrations less than about $0.022 \mathrm{M}$, solutions of cobaltodihistidine were observed to obey Beer's law with a molar extinction coefficient of $37.2 \mathrm{l} \cdot \mathrm{mole}^{-1}$. $\mathrm{cm}^{-1}$ at $\lambda=486 \mathrm{~m} \mu$. Again, this value is somewhat higher than the value of $18.4 \mathrm{l}$. mole ${ }^{-1} \cdot \mathrm{cm}^{-1}$ as reported by HEARON et $a l .{ }^{18}$, but it should be noted that the optical path length chosen by these workers in a similar experiment was the inside diameter of the Thumberg tube which is incorrect in view of the results obtained for the equivalent path length of such a tube during this study. For concentrations greater than about $0.022 \mathrm{M}$, a white precipitate was observable in the test solution and the absorbance of the solution increased above that predicted by Beer's law. Samples in this concentration region were centrifuged and the absorbance of the supernatant was determined. For sample concentrations greater than $0.022 \mathrm{M}$, the absorbance of the centrifuged liquid was found to be constant, indicating that the measured concentration was the solubility concentration of cobaltodihistidine in water at $25^{\circ}$. These observations substantiate the experimental results obtained for the oxygen flux measurements and indicate that it is the solubility of the unoxygenated carrier form that limits the facilitation effect in the cobaltodihistidine-oxygen system.

\section{Effect of temperature}

In order to elucidate further the nature of the transport process, an Arrheniustype plot was constructed in which the logarithm of the facilitation increment was plotted against inverse temperature. The result is presented in Fig. II. At total carrier concentration of $0.0{ }_{5} \mathrm{M}$ and an upstream oxygen pressure of 20 inches $\mathrm{Hg}$, the data indicate a linear relation between the variables with an apparent activation energy of $5.44 \mathrm{kcal} / \mathrm{mole}$. Similar plots for the diffusivity of oxygen and nitrogen in water yield activation energies of 2.9 and $I .9 \mathrm{kcal} / \mathrm{mole}$, respectively. The activation energy associated with the decomposition reaction of oxy-bis(cobaltodihistidine) and
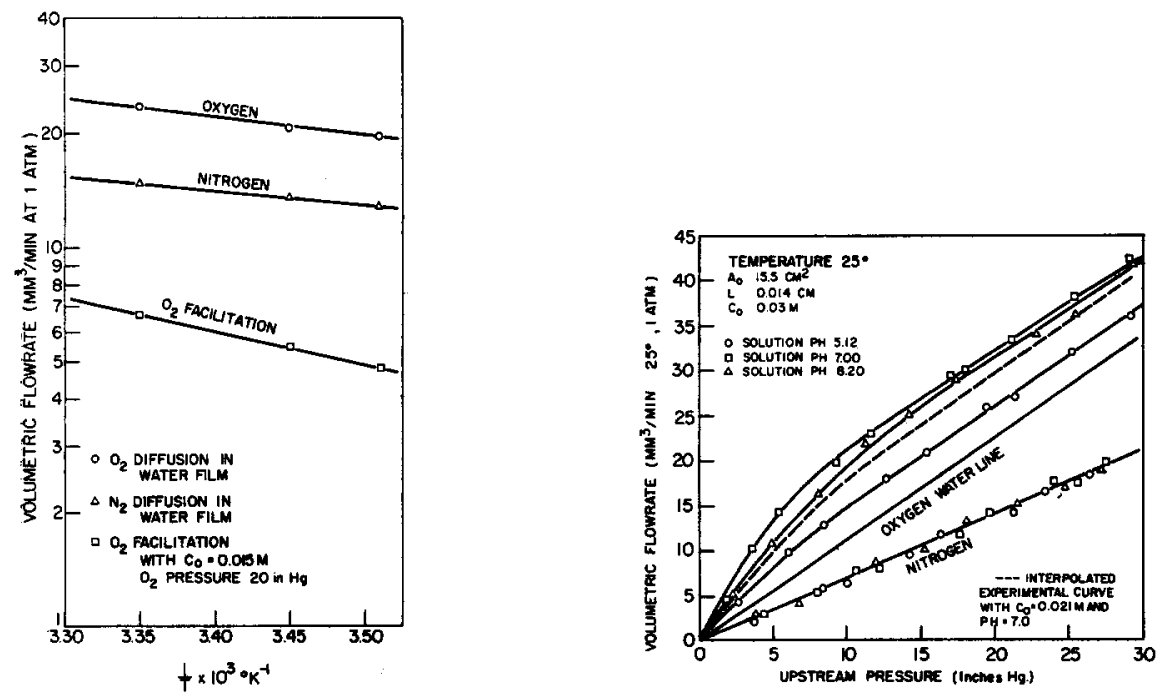

Fig. I1. Effect of temperature on facilitation.

Fig. I2. Effect of solution $\mathrm{pH}$ on oxygen transport. 
oxygen is $26.0 \mathrm{kcal} / \mathrm{mole}$ and the activitation energy of the first-step reaction of cobaltodihistidine and oxygen is $5.6 \mathrm{kcal} / \mathrm{mole}^{19}$. Based on these considerations, the facilitated transport mechanism appears to be governed mainly by a diffusive-type process with an indication that the first-step reaction of cobaltodihistidine and oxygen may be rate controlling.

\section{Effect of solution $p H$}

Since the formation reaction of cobaltodihistidine involves the production of hydrogen ions, the $\mathrm{pH}$ of the solution should affect the total amount of carrier in the system and hence the observed oxygen transport. At $25^{\circ}$, solutions of cobaltodihistidine were prepared with $C_{0}=0.03 \mathrm{M}$ and the $\mathrm{pH}$ of the solutions was adjusted using a standard $\mathrm{NaOH}$ solution. Solution $\mathrm{pH}$ values of $5 . \mathrm{I} 2,7.00$ and 8.20 were investigated and the results are presented in Fig. I2. At a solution $\mathrm{pH}$ of 5.I2, which is obtained by mixing the stock solutions of cobaltous chloride and histidine without the addition of $\mathrm{NaOH}$, a flux curve similar in shape to that obtained at a solution $\mathrm{pH}$ of 7.00 was observed, but each oxygen flux was reduced considerably at each value of the upstream oxygen pressure. For a given oxygen pressure, the observed oxygen flux through a $\mathrm{pH} 8.20$ solution was never above that obtained for the $\mathrm{pH} 7.00$ solution. In fact, in certain regions of oxygen pressure, the observed flux was depressed and indicates the possible breakdown of the histidine structure in the alkaline medium with the subsequent evolution of carbon dioxide ${ }^{18}$. It thus appears that the optimal $\mathrm{pH}$ for oxygen transport in cobaltodihistidine solutions is in the region of 7.00 .

Based on the chemical equilibria involved in the formation of cobaltodihistidine and oxy-bis (cobaltodihistidine), it is possible to calculate the equivalent value of available carrier $C_{0}$ at a given solution $\mathrm{pH}$ and oxygen pressure. As the $\mathrm{pH}$ of the solution is reduced, less total carrier is available for the transport process since a portion of the carrier is in the unbound or ionic state. At a solution $\mathrm{pH}$ of 5.12 , the effective value of $C_{0}$ is calculated to be $0.02 \mathrm{I} \mathrm{M}$ based on a total value of $0.03 \mathrm{M}$, and the ionization constants for Reactions $A$ and $B$ given above. The interpolated flux curve corresponding to this value of $C_{0}$ is indicated by the dashed line in Fig. I2. For each value of the upstream oxygen pressure, the observed oxygen flux was less than the interpolated experimental value. Apparently there is a more complex interaction between $\mathrm{pH}$ and facilitation than simply reducing the available carrier concentration, and perhaps $\mathrm{pH}$ gradients are established in the membrane.

\section{THEORETICAL ANALYSIS}

\section{Diffusion and reaction equations}

The geometry and nomenclature for the experimental system is shown in Fig. I3 and typical concentration profiles of the various components in the membrane are given in Fig. I6.

An analysis of the facilitation process starts with making mass balances in the membrane. The mass balance equations within the membrane are

$$
D_{\mathrm{A}} \frac{\mathrm{d}^{2} C_{\mathrm{A}}}{\mathrm{d} x^{2}}+r_{\mathrm{A}}=\mathrm{o}
$$




$$
\begin{aligned}
& D_{\mathrm{B}} \frac{\mathrm{d}^{2} C_{\mathrm{B}}}{\mathrm{d} x^{2}}+r_{\mathrm{B}}=\mathrm{o} \\
& D_{\mathrm{C}} \frac{\mathrm{d}^{2} C_{\mathrm{C}}}{\mathrm{d} x^{2}}+r_{\mathrm{C}}=\mathrm{o}
\end{aligned}
$$

where the $D$ 's are the diffusion coefficients of the species and the $r$ 's are the rates of generation of the various components by chemical reaction. These mass balances are general for this system and apply to both the equilibrium and nonequilibrium models.

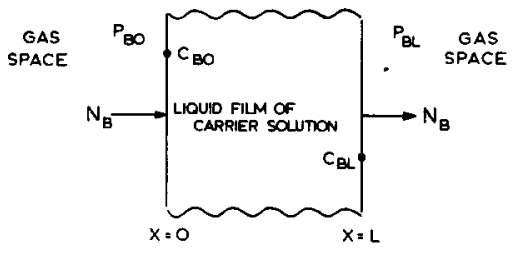

(A)

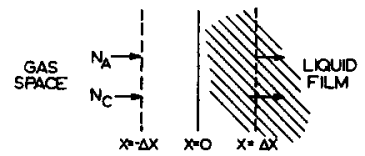

(B)

Fig. 13. (A) Experimental geometry and definition of symbols for transported species "B". (B) Boundary considerations for carrier species " $A$ " and " $C$ ".

Writing the overall rates of formation of each component by chemical reaction, and letting $\mathrm{A}=$ cobaltodihistidine, $\mathrm{B}=$ molecular oxygen, $\mathrm{C}=\mathrm{oxy}$-bis(cobaltodihistidine) and $\mathrm{AB}=$ intermediate complex, we obtain for any position in the membrane:

$$
\begin{aligned}
& r_{\mathrm{A}}=-k_{1} C_{\mathrm{A}} C_{\mathrm{B}}+k_{-1} C_{\mathrm{AB}}-k_{2} C_{\mathrm{AB}} C_{\mathrm{A}}+k_{-2} C_{\mathrm{C}} \\
& r_{\mathrm{B}}=-k_{\mathbf{1}} C_{\mathrm{A}} C_{\mathrm{B}}+k_{-1} C_{\mathrm{AB}} \\
& r_{\mathrm{AB}}=k_{1} C_{\mathrm{A}} C_{\mathrm{B}}-k_{-1} C_{\mathrm{AB}}-k_{2} C_{\mathrm{AB}} C_{\mathrm{A}}+k_{-2} C_{\mathrm{C}} \\
& r_{\mathrm{C}}=k_{2} C_{\mathrm{AB}} C_{\mathrm{A}}-k_{-2} C_{\mathrm{C}}
\end{aligned}
$$

Assuming the pseudo-steady-state condition for no build-up of $\mathrm{AB}, \boldsymbol{r}_{\mathrm{AB}}=\mathrm{o}$ and

$$
C_{\mathrm{AB}}=\frac{k_{1} C_{\mathrm{A}} C_{\mathrm{B}}+k_{-2} C_{\mathrm{C}}}{k_{-1}+k_{2} C_{\mathrm{A}}}
$$

The intermediate complex $\mathrm{AB}$ is ignored in the development of the mass balance equations and hence this mathematical model is only valid for negligibly small values of $C_{\mathrm{AB}}$. However, this requirement is an integral part of the pseudo-steady-state assumption, since it assumes $k_{-1}$ and $k_{2}$ are very large compared to $k_{1}$ and $k_{-2}$ which ensures negligibly small values of $C_{\mathrm{AB}}$. It should be noted that if the presence of $\mathrm{AB}$ cannot be ignored then it also would contribute to the facilitated diffusion of oxygen and would add directly to the overall diffusive flux.

Substituting the obtained steady-state value of $C_{\mathrm{AB}}$ into the remaining rate expressions:

$$
\begin{aligned}
& r_{\mathrm{A}}=\frac{-2 k_{1} k_{2} C_{\mathrm{A}}^{2} C_{\mathrm{B}}+2 k_{-1} k_{-2} C_{\mathrm{C}}}{k_{-1}+k_{2} C_{\mathrm{A}}} \\
& r_{\mathrm{B}}=-r_{\mathrm{C}}=\frac{r_{\mathrm{A}}}{2}
\end{aligned}
$$


A

Also we have that

$$
\frac{k_{1} k_{2}}{k_{-1} k_{-2}}=K_{2}
$$

so that the unknown constants $k_{2}$ and $k_{-1}$ can be eliminated. Adding Eqns. I and 3 and eliminating the chemical reaction term by Eqn. ro

$$
D_{\mathrm{A}} \frac{\mathrm{d}^{2} C_{\mathrm{A}}}{\mathrm{d} x^{2}}+2 D_{\mathrm{C}} \frac{\mathrm{d}^{2} C_{\mathrm{C}}}{\mathrm{d} x^{2}}=0
$$

Also, we can obtain

$$
D_{\mathrm{B}} \frac{\mathrm{d}^{2} C_{\mathrm{B}}}{\mathrm{d} x^{2}}+D_{\mathrm{C}} \frac{\mathrm{d}^{2} C_{\mathrm{C}}}{\mathrm{d} x^{2}}=\mathrm{o}
$$

Integrating these equations twice gives

$$
\begin{aligned}
& D_{\mathrm{A}} C_{\mathrm{A}}+2 D_{\mathrm{C}} C_{\mathrm{C}}=\alpha_{1} x+\alpha_{3} \\
& D_{\mathrm{B}} C_{\mathrm{B}}+D_{\mathrm{C}} C_{\mathrm{C}}=\alpha_{2} x+\alpha_{4}
\end{aligned}
$$

which along with Eqn. I give a new set of equations to be solved, one differential equation and two algebraic.

Insofar as boundary conditions are concerned, the oxygen partial pressure at each membrane surface is fixed experimentally. Therefore, by Henry's law

$$
\begin{array}{ll}
\text { at } x=0: & C_{\mathrm{B}}=P_{\mathrm{BO}} / H=C_{\mathrm{BO}} \\
\text { at } x=L: & C_{\mathrm{B}}=P_{\mathrm{BL}} / H=C_{\mathrm{BL}}
\end{array}
$$

where $H$ is the Henry's law constant for oxygen and $P_{\mathrm{BO}}, P_{\mathrm{BL}}$ are partial pressures of oxygen in the gas on each side of the film.

However, boundary conditions on the carrier species $C_{\mathbf{A}}$ and $C_{\mathbf{C}}$ are not as obvious and require further analysis.

\section{Boundary conditions}

Clearly, the carrier molecule whether in the free or combined form cannot leave the liquid film. In most cases, it is an organic molecule with negligible vapor pressure and hence can be considered a nonvolatile constituent of the system. Thus, any mathematical boundary conditions must account for the fact that the carrier in all its forms is constrained to the liquid film. Consider the following mass balance on a differential element straddling a gas-liquid interface, Fig. I3, where Component B is the only component which enters and leaves the liquid film from the gas phase:

$$
\begin{aligned}
& \text { Balance on C: } N_{\mathrm{C}} A_{0}\left|-\Delta x-N_{\mathrm{C}} A_{0}\right| \Delta x \frac{r_{\mathrm{A}}}{2} A_{0} \Delta x=\mathrm{o} \\
& \text { Balance on } \mathrm{A}: N_{\mathrm{A}} A_{0}\left|-\Delta x-N_{\mathrm{A}} A_{0}\right|_{\Delta x}+r_{\mathrm{A}} A_{0} \Delta_{x}=\mathrm{o}
\end{aligned}
$$

where $N_{\mathrm{A}}, N_{\mathrm{C}}$ are the fluxes of the carrier species, moles $\cdot \mathrm{cm}^{-\mathbf{2}} \cdot \mathrm{sec}^{-1}$, and $A_{\mathrm{o}}$ is the cross-sectional area of the film.

Clearly, $N_{\mathrm{C}} \mid-\Delta x=0$ and $N_{\mathrm{A}} \mid-\Delta x=0$ since no $\mathrm{C}$ or A enters the liquid film from the gas space. Hence, as $\Delta x$ approaches zero and if $r_{\mathbf{A}}$ is finite,

$$
\operatorname{Lim}_{\Delta x \rightarrow 0} N_{\mathrm{C}}\left|\Delta x=0 \quad \operatorname{Lim}_{\Delta x \rightarrow 0} N_{\mathrm{A}}\right| \Delta \mathrm{x}=0
$$


Thus, it appears that the correct boundary conditions for such a system are that the fluxes of all nonvolatile species must individually be zero at the gas-liquid interfaces. This development is valid as long as the liquid layer at the interface is not considered to be different from the bulk liquid phase. In other words, it does not behave as a catalytic surface for the chemical reaction and does not possess physical properties which are different from the bulk liquid. But if the reaction rate constants are allowed to become very large, then $r_{A}$, the net reaction rate, is no longer finite but becomes indeterminate ${ }^{29,30}$. That is, as the reaction becomes closer to being "at equilibrium", the boundary conditions as represented by Eqn. I9 are no longer valid.

\section{Equilibrium vs. nonequilibrium}

A major point of conflict in the current theoretical treatment of facilitated transport systems is whether or not "true" chemical equilibrium can exist at all points within the liquid film. Of course, there are two rate processes occurring simultaneously in facilitated transport systems, diffusion and chemical reaction. Thus, one might expect that, if the chemical reaction rates were large compared to the rates of molecular diffusion, chemical equilibrium could exist at all points within the liquid layer even at the interface. This theory has found wide acceptance in the literature and several mathematical models have been developed for equilibrium carrier systems ${ }^{1,2,30,31}$.

If one applies the concept of chemical equilibrium as usually considered in a batch system in which no material enters or leaves the system, $r_{\mathbf{A}}=$ o everywhere in the membrane and the mathematical solutions for the concentration profiles from Eqns. 1,2 and 3 become

$$
\begin{aligned}
& C_{\mathbf{A}}(x)=\beta_{1} x+\beta_{2} \\
& C_{\mathrm{C}}(x)=\beta_{3} x+\beta_{4} \\
& C_{\mathbf{B}}(x)=\beta_{5} x+\beta_{6}
\end{aligned}
$$

However, the equilibrium constant relation, $K_{2}=C_{\mathrm{C}} / C_{\mathrm{A}}{ }^{2} C_{\mathrm{B}}$, demands that these linear profiles cannot exist simultaneously in the liquid film and that the only consistent mathematical solution to the problem is constant concentrations of all species across the film. This argument also applies to systems with more general stoichiometry. The apparent contradiction is a result of the interpretation of equilibrium in an "open system" in which material is allowed to cross the system boundaries. Thus, it is incorrect to say that the existence of chemical equilibrium in such a system implies that the overall rate of reaction of each species is identically zero. This argument was first proposed by OLANDER ${ }^{30}$ and has been confirmed by GoDDARD et al. ${ }^{29}$. Therefore, the correct interpretation is that the overall rate of reaction term becomes indeterminate near the interface in the approach to equilibrium and cannot be treated as a finite quantity. Consider again the mass balances of the nonvolatile species $\mathrm{A}$ and $\mathrm{C}$ as depicted before in a liquid layer near the gas-liquid interface:

$$
\begin{aligned}
& -N_{\mathrm{C}} \mid \Delta x-\frac{r_{\mathrm{A}}}{2} \Delta x=0 \\
& -N_{\mathrm{A}} \mid \Delta x+r_{\mathrm{A}} \Delta x=\mathrm{o}
\end{aligned}
$$

If the chemical reaction rates are infinitely rapid compared with diffusional rates, then $r_{\mathrm{A}}$ becomes indeterminate and the proper boundary condition at each interface 
is obtained by adding the above equations to eliminate the reaction term, i.e. $N_{\mathrm{A}}+$ $2 N_{\mathrm{C}}=0$. It therefore appears that two models are appropriate for systems of this type: the equilibrium model, applicable if the system reaction rates are sufficiently large compared to diffusional rates, and the nonequilibrium model, applicable when the chemical reaction rates and diffusional rates are of comparable magnitude.

FRIEDLANDER AND KELLER ${ }^{7}$ and others ${ }^{3}$ have shown how to calculate facilitated fluxes in the near equilibrium region at low diffusion driving forces. GodDARD et al. ${ }^{29}$ have generalized the treatment for the case of the near equilibrium region involving large driving forces.

\section{Numerical solution of flux equations}

In the case of the equilibrium model, the mathematical model becomes independent of the reaction kinetics and the mass balance Eqns. I, 2 and 3 can be replaced by the following set of equations:

$$
\begin{aligned}
& D_{\mathrm{A}} C_{\mathrm{A}}+2 D_{\mathrm{C}} C_{\mathrm{C}}=\alpha_{3} \\
& D_{\mathrm{B}} C_{\mathrm{B}}+D_{\mathrm{C}} C_{\mathrm{C}}=\alpha_{2} x+\alpha_{4} \\
& K_{2}=C_{\mathrm{C}} / C_{\mathrm{A}^{2}} C_{\mathrm{B}}
\end{aligned}
$$

These equations apply at all points within the liquid film where the chemical reaction rates are infinitely rapid compared to diffusional rates. The associated boundary conditions are:

$$
\begin{array}{ll}
\text { at } x=\mathrm{o}: & C_{\mathrm{B}}=C_{\mathrm{BO}}=P_{\mathrm{BO}} / H \\
\text { at } x=L: & C_{\mathrm{B}}=C_{\mathrm{BL}}=P_{\mathrm{BL}} / H
\end{array}
$$

where $H$ is the Henry's law constant for B. In addition, a total carrier balance yields

$$
\int_{0}^{L}\left(C_{\mathrm{A}}+2 C_{\mathrm{C}}\right) \mathrm{d} x=C_{0} L
$$

where $C_{0}$ is the total carrier concentration in the system initially. It should be noted that the importance of this overall material balance had not been recognized because previous analyses of the facilitated transport problem were limited to cases where the carrier diffusivities were equal, i.e. $D_{\mathrm{A}}=D_{\mathrm{C}}$. For this limiting case, from Eqn. 23 we obtain $\left(C_{\mathrm{A}}+2 C_{\mathrm{C}}\right)=\alpha_{3} / D_{\mathrm{A}}$, substituting this in the integral of Eqn. 27 gives the result that $\alpha_{3}=C_{0} D_{\mathrm{A}}$, or that $C_{\mathrm{A}}+2 C_{\mathrm{C}}=C_{0}$ everywhere in the liquid film.

The concentration profiles and fluxes for the equilibrium model are best determined from Eqns. 24-27 by a numerical technique. Using the notation

$$
\begin{array}{lll}
\text { at } x=\mathrm{o}: & C_{\mathrm{A}}=C_{\mathrm{AO}}, & C_{\mathrm{C}}=C_{\mathrm{CO}} \\
\text { at } x=\mathrm{L}: & C_{\mathrm{A}}=C_{\mathrm{AL}}, & C_{\mathrm{C}}=C_{\mathrm{CL}}
\end{array}
$$

the constants $\alpha_{2}, \alpha_{3}, \alpha_{4}$ can be expressed in terms of these concentrations.

$$
\begin{aligned}
& \alpha_{3}=D_{\mathrm{A}} C_{\mathrm{AL}}+2 D_{\mathrm{C}} C_{\mathrm{CL}}=D_{\mathrm{A}} C_{\mathrm{AO}}+2 D_{\mathrm{C}} C_{\mathrm{CO}} \\
& \alpha_{4}=D_{\mathrm{B}} C_{\mathrm{BO}}+D_{\mathrm{C}} C_{\mathrm{CO}} \\
& \alpha_{2}=\frac{D_{\mathrm{B}}}{L}\left(C_{\mathrm{BL}}-C_{\mathrm{BO}}\right)+\frac{D_{\mathrm{C}}}{L}\left(C_{\mathrm{CL}}-C_{\mathrm{CO}}\right)
\end{aligned}
$$


Note that $-\alpha_{2}$ is the total flux of oxygen through the membrane for both the equilibrium and nonequilibrium models.

Also, Eqns. 24 and 25 can be solved for $C_{\mathrm{A}}$ and $C_{\mathrm{C}}$ in terms of $C_{\mathrm{B}}$

$$
C_{\mathrm{C}}=\frac{\alpha_{2} x+\alpha_{4}-D_{\mathrm{B}} C_{\mathrm{B}}}{D_{\mathrm{C}}}, C_{\mathrm{A}}=\frac{\alpha_{3}-2\left(\alpha_{2} x+\alpha_{4}-D_{\mathrm{B}} C_{\mathrm{B}}\right)}{D_{\mathrm{A}}}
$$

and these expressions can be substituted into the total carrier balance Eqn. 27 to obtain

$$
\frac{\left(\left(\alpha_{3}-2 \alpha_{4}\right) D_{\mathrm{C}}+2 \alpha_{4} D_{\mathrm{A}}\right) L}{D_{\mathrm{A}} D_{\mathrm{C}}}+\alpha_{2}\left(\frac{\mathrm{I}}{D_{\mathrm{C}}}-\frac{\mathrm{I}}{D_{\mathrm{A}}}\right)+{ }_{2} D_{\mathrm{B}}\left(\frac{\mathrm{I}}{D_{\mathrm{A}}}-\frac{\mathrm{I}}{D_{\mathrm{C}}}\right) \int_{0}^{\mathrm{L}} C_{\mathrm{B}} \mathrm{d} x=C_{0} L(30)
$$

The numerical method of solution is as follows:

(I) choose a value for $C_{\mathrm{CL}} ;$ (2) calculate $C_{\mathrm{AL}}=\sqrt{C_{\mathrm{CL}} / K C_{\mathrm{BL}}}$ by Eqn. 26 ; (3) calculate $\alpha_{3}$ by Eqn. $28 \mathrm{a} ;$ (4) calculate $C_{\mathrm{CO}}=\left[\alpha_{3}-D_{\mathrm{A}}\left(C_{\mathrm{CO}} / K C_{\mathrm{BO}}\right)^{1 / 2}\right] / 2 D_{\mathrm{C}} ;(5)$ calculate $\alpha_{4}$ by Eqn. 28b; (6) calculate $\alpha_{2}$ by Eqn. 28c.

Now, all the constants are determined in terms of the applied boundary conditions for $C_{\mathrm{B}}$ and an arbitrary value for $C_{\mathbf{C L}}$. The oxygen concentration profile as a function of position in the membrane is found by dividing the membrane into increments of thickness and solving Eqns. 24, 25 and 26 simultaneously at each of the $n+\mathbf{I}$ positions using a half-interval trial and error technique. Once this profile has been determined, then Eqn. 30 can be solved to obtain a corresponding value of $C_{0}$, the total carrier concentration initially present in the system. The integral term in Eqn. 30 is determined by using a Simpson's rule sub-routine. Thus a functional relationship can be determined between $-\alpha_{2}$, the total oxygen flux through the system and $C_{0}$ for fixed values of $C_{\mathbf{B L}}$ and $C_{\mathbf{B O}}$. The procedure is repeated for different values of the quantities $C_{\mathbf{B O}}, C_{\mathrm{BL}}$ and $C_{\mathrm{CL}}$ within the region of experimental interest. The obtained relationships can then be cross-plotted to display the results in a form which is directly comparable with the experimental data, namely $-\alpha_{2}$ vs. $C_{\mathrm{BL}}$ with $C_{\mathrm{o}}$ and $C_{\mathrm{BO}}$ as parameters. In the experiments reported here, $C_{\mathrm{BO}}$ always had the value zero.

In the case of the nonequilibrium model, the mass balance Eqns. I, 2 and 3 must be retained and the derived expression for the overall rate of chemical reaction must be inserted into Eqn. 2. The resulting system of equations becomes:

$$
\begin{aligned}
& D_{\mathrm{A}} C_{\mathrm{A}}+{ }_{2} D_{\mathrm{C}} C_{\mathrm{C}}=\alpha_{3} \\
& D_{\mathrm{B}} C_{\mathrm{B}}+D_{\mathrm{C}} C_{\mathrm{C}}=\alpha_{2} x+\alpha_{4} \\
& D_{\mathrm{B}} \frac{\mathrm{d}^{2} C_{\mathrm{B}}}{\mathrm{d} x^{2}}+\frac{-K_{2} k_{-2} C_{\mathrm{B}}+k_{-2} C_{\mathrm{C}}}{\mathrm{I}+\frac{K_{2} k_{-2}}{k_{1}} C_{\mathrm{A}}}=0
\end{aligned}
$$

In this case, since

$$
\left.\frac{\mathrm{d} C_{\mathrm{C}}}{\mathrm{d} x}\right|_{x=0}=\left.\frac{\mathrm{d} C_{\mathrm{A}}}{\mathrm{d} x}\right|_{x=0}=\left.\frac{\mathrm{d} C_{\mathrm{C}}}{\mathrm{d} x}\right|_{x=\mathrm{L}}=\left.\frac{\mathrm{d} C_{\mathrm{A}}}{\mathrm{d} x}\right|_{x=\mathrm{L}}=0
$$

the boundary conditions are:

$$
\begin{aligned}
& \text { at } x=0: D_{\mathrm{B}} \frac{\mathrm{d} C_{\mathrm{B}}}{\mathrm{d} x}=\alpha_{2} \\
& \text { at } x=L: D_{\mathrm{B}} \frac{\mathrm{d} C_{\mathrm{B}}}{\mathrm{d} x}=\alpha_{2}
\end{aligned}
$$


Again, the total carrier balance yields:

$$
\int_{0}^{\mathrm{L}}\left(C_{\mathrm{A}}+2 C_{\mathrm{C}}\right) \mathrm{d} x=C_{0} L
$$

These equations apply to systems in which the chemical reaction rates are not infinitely rapid compared to diffusional rates and thus cannot be ignored in the modeling of the system.

Using Eqns. 3I and 32, Eqn. 33 can be written solely in terms of $C_{\mathbf{B}}$. The result is

$$
D_{\mathrm{B}} \frac{\mathrm{d}^{2} C_{\mathrm{B}}}{\mathrm{d} x^{2}}=\frac{\frac{K_{2} k_{-2}}{D_{\mathrm{A}}{ }^{2}}\left[\alpha_{3}-2\left(\alpha_{2} x+\alpha_{4}-D_{\mathrm{B}} C_{\mathrm{B}}\right)\right]^{2} C_{\mathrm{B}}-\frac{k_{-2}}{D_{\mathrm{C}}}\left(\alpha_{2} x+\alpha_{4}-D_{\mathrm{B}} C_{\mathrm{B}}\right)}{\mathrm{I}+\frac{K_{2} k_{-2}}{D_{\mathrm{A}} k_{1}}\left[\alpha_{3}-2\left(\alpha_{2} x+\alpha_{4}-D_{\mathrm{B}} C_{\mathrm{B}}\right)\right]}
$$

The integral condition becomes:

$$
\frac{\left(\alpha_{3}-2 \alpha_{4}\right) D_{\mathrm{C}}+2 \alpha_{4} D_{\mathrm{A}}}{D_{\mathrm{A}} D_{\mathrm{C}}}+\alpha_{2} L \frac{D_{\mathrm{A}}-D_{\mathrm{C}}}{D_{\mathrm{A}} D_{\mathrm{C}}}+\frac{2 D_{\mathrm{B}}}{L}\left(\frac{D_{\mathrm{C}}-D_{\mathrm{A}}}{D_{\mathrm{A}} D_{\mathrm{C}}}\right) \int_{0}^{L} C_{\mathrm{B}}(x) \mathrm{d} x=C_{0}
$$

For fixed values of $\alpha_{2}, \alpha_{3}$ and $\alpha_{4}$, Eqns. 36 and 37 can be solved numerically. Eqn. 36 was solved numerically using a fourth-order Runge-Kutta technique which, for fixed values of $\alpha_{2}$ and $\alpha_{3}$, determined the proper value of $\alpha_{4}$ to satisfy the boundary conditions. The comparison criterion used in the iteration technique was the requirement that the slopes of the calculated oxygen concentration profile be equal at $x=0$ and $x=L$. For a given assumed value of $\alpha_{4}$, solutions can be obtained for the system of mathematical equations for some film thickness $L^{*}$, not necessarily equal to $L$, the desired diffusional path length. It was observed that as $\alpha_{\mathbf{4}}$ was incrementally increased, $L^{*}-L$ approached zero and the desired solution was obtained. The convergence of the numerical solutions to the proper path length was found to be extremely sensitive to the initial choice of $\alpha_{4}$ and to the magnitude of the incremental increase in $\alpha_{4}$. In the numerical solutions obtained, $\alpha_{4}$ was of the order of $\mathrm{I} \cdot \mathrm{IO}^{-12}$ moles $\cdot \mathrm{cm}^{-1} \cdot \mathrm{sec}^{-1}$ and, for the fixed values of $\alpha_{2}$ and $\alpha_{3}$, convergence of the numerical technique required the specification of $\alpha_{4}$ te the third and sometimes fourth decimal place.

Once the oxygen concentration profile was determined, then Eqn. 37 was solved using a Simpson's rule technique to evaluate the integral component of the equation. Thus a functional relationship was developed between $C_{\mathrm{BL}}$ and $C_{\mathrm{o}}$ with $\alpha_{2}$, the total oxygen flux through the system, as a parameter. The derived numerical predictions were then cross-plotted to present the results in a form directly comparable with the experimental data. Since the oxygen partial pressure was maintained at zero on one side of the membrane in all the experiments, $C_{\mathrm{BO}}=0$ in the calculations performed.

Both of these numerical methods are easily generalized and can be applied to systems of complex stoichiometry and where the diffusive coefficients of the species are all different.

The overall flux of oxygen through the film is given by

$$
\text { Flux of oxygen }=-\alpha_{2}=\frac{D_{\mathbf{B}}}{L}\left(C_{\mathrm{BO}}-C_{\mathrm{BL}}\right)+\frac{D_{\mathrm{C}}}{L}\left(C_{\mathrm{CO}}-C_{\mathrm{CL}}\right)
$$


We will refer to $\left(D_{\mathrm{C}} / L\right)\left(C_{\mathrm{CO}}-C_{\mathrm{CL}}\right)$ as the facilitated component. It is the increment in flux over that expected by simple diffusion without carriers.

\section{Results of nonequilibrium model}

Preliminary numerical results indicated that the mathematical solutions for the component concentration profiles were extremely sensitive to assumed values of various system parameters involving the concentrations of the carrier forms at the gas-liquid interfaces. The method of solution adopted was one of trial and error and the sensitivity of the model to the assumed parameters often resulted in unrealistic solutions. Due to the form of the mathematical equations, solutions were most easily obtained for the total carrier concentration $C_{0}$ as a function of the upstream oxygen pressure (the downstream oxygen pressure was assumed as zero) with the total oxygen flux as a mathematical parameter. The numerical results obtained are indicated in Fig. I4. In these numerical calculations, the values of the variables were chosen to "bracket" the experimental range of the corresponding system variables. The curves of Fig. I4 were then cross-plotted along lines of constant carrier concentration (as illustrated by the dashed line) to obtain the data in a form directly comparable with the experimental results. A comparison of the predictions of the theoretical model with the experimental data is indicated in Fig. I5. The agreement between the predictions of the nonequilibrium model and the experimental data is quite good and indicates the applicability of this model to the cobaltodihistidine-oxygen system.
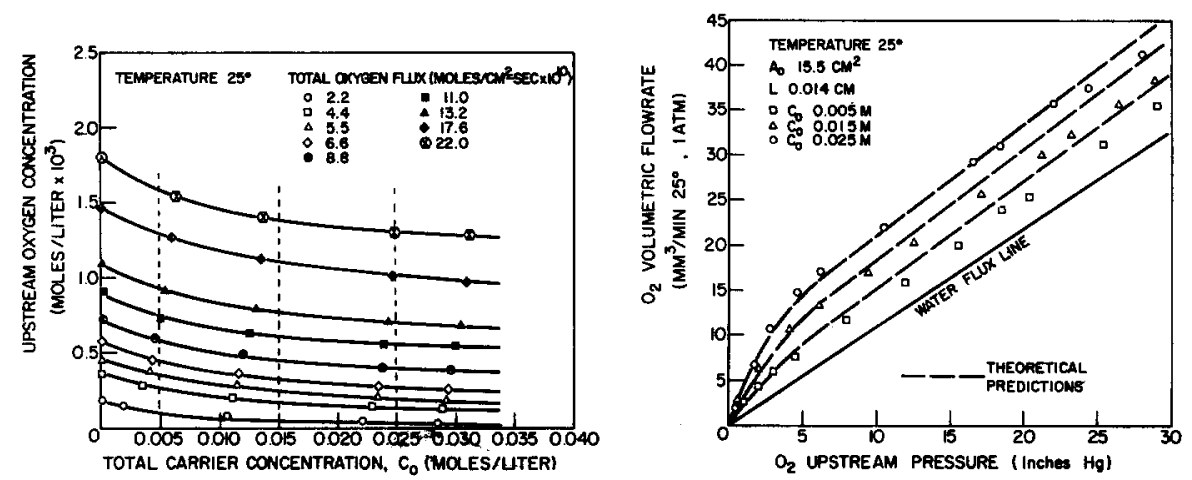

Fig. I4. Numerical solutions for the nonequilibrium model.

Fig. 15. Comparison of nonequilibrium model predictions with experimental results.

It should be noted that this model is based on seven parameter values, either published in the literature or measured during the course of this work. The values used for the reaction rate constants were those published by Simplicio AND WILKIns ${ }^{19}$, the value of the equilibrium constant was that determined by HEARoN et al. ${ }^{18}$. The diffusion coefficients of the reversible carrier forms, $0.55 \cdot 10^{-5} \mathrm{~cm}^{2} / \mathrm{sec}$ and $0.34 \cdot 10^{-5} \mathrm{~cm}^{2} / \mathrm{sec}$ for the free and oxygenated forms of cobaltodihistidine, and oxygen $\left(2.0^{\cdot} \cdot \mathrm{IO}^{-5} \mathrm{~cm}^{2} / \mathrm{sec}\right)$ all at $25^{\circ}$ and the tortuosity (r.o) of the membrane were determined during the course of this work ${ }^{17}$. In view of this, the authors feel that the agreement of the nonequilibrium model with the experimental data is quite remarkable.

The greatest deviation of the model (about $15 \%$ ) occurs at low values of the 
carrier concentration and at high upstream oxygen pressures. However, at a fixed upstream oxygen pressure, the predicted fluxes agree more closely with the corresponding experimental results as $C_{0}$ increases. It should be noted that, for a fixed value of $C_{0}$, the model predicts an oxygen flux curve that is not parallel to the water flux line for oxygen but deviates positively from it. The experimental data also deviate from a line parallel to the water flux line but in the opposite direction. Thus, the resultant deviation between the model prediction and the experimental data is greatest at high oxygen pressures while the agreement is quite good at lower values of oxygen pressure. The main conclusion to be drawn from these results is that the nonequilibrium model is apparently applicable to the cobaltodihistidine-oxygen system in which the chemical reaction rates are not infinitely rapid compared to the diffusional rates realized in the sytem.

The resultant concentration profile shapes were as expected and a typical set of profiles is presented in Fig. I6. It should be noted that the profiles of the nonvolatile species $\mathrm{A}$ and $\mathrm{C}$ are flat near the system boundaries and that the inflection point, $x^{\star}$, represents a point where the component concentrations are in the ratio given by the equilibrium constant relation. The profiles indicate that in the region to the left of the "equilibrium plane", oxygen and cobaltodihistidine are being consumed and oxy-bis(cobaltodihistidine) is being produced while to the right of this plane the opposite net reaction is taking place. This is a result of the change in the sign of the overall rate of reaction which occurs at $x=x^{\star}$. At this point of equilibrium, the molar fluxes of oxygen and oxy-bis(cobaltodihistidine) are maximal while that of cobaltodihistidine is at a minimum. The condition of steady state requires the slopes of the oxygen concentration profile to be equal at the system boundaries since it is the only component that enters or leaves the sytem. It should also be noted that the total carrier concentration at each position in the membrane $\left(C_{\mathrm{B}}+2 C_{\mathrm{c}}\right)$ is not constant throughout the membrane.
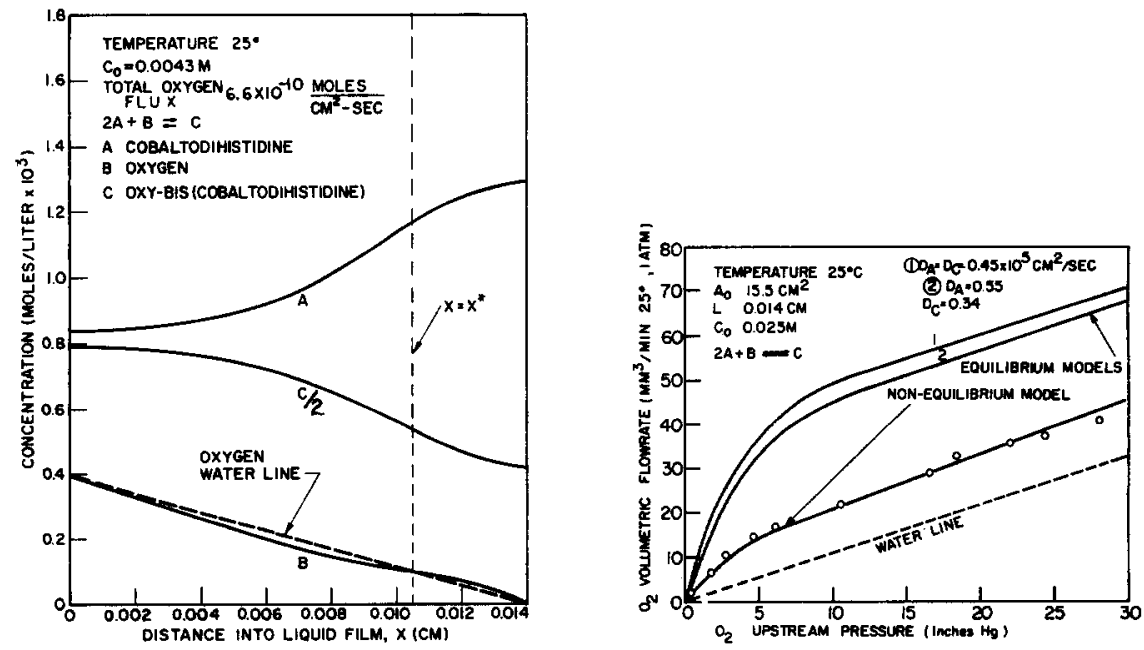

Fig. I6. Typical concentration profiles of nonequilibrium model.

Fig. 17. Comparison of equilibrium and nonequilibrium models with experimental results. 


\section{Results of the equilibrium model}

The corresponding equilibrium model was solved numerically on the IBM Model 360 digital computer by the method previously indicated. The fluxes predicted by the equilibrium model were found to be many times larger than observed experimentally under similar system conditions. A comparison of the flux curves predicted by the equilibrium model and the nonequilibrium model with the experimental data is presented in Fig. I7. The results clearly indicate that the physical system is governed by the restraints of the nonequilibrium model and not by those of the equilibrium model. Thus, the cobaltodihistidine-oxygen transport system cannot be considered to be at equilibrium for the range of conditions studied here since the associated chemical reaction rates are not infinitely rapid compared to the diffusional rates of the system.

For systems in which the aqueous diffusion coefficients of the reversible carrier forms are approximately equal, the expected degree of facilitation can be calculated for the equilibrium model from the saturation curve of the system. This is the case in the hemoglobin-oxygen system in which the molecular weight of the reversible carrier forms are 68000 and $68032 \mathrm{~g} / \mathrm{mole}$, respectively, and the aqueous diffusion coefficients are nearly equal. However, in the cobaltodihistidine-oxygen system, the diffusion coefficients of the reversible carrier forms differ by a factor of I.62. Assuming an equal diffusivity value of $0.45 \cdot 10^{-5} \mathrm{~cm}^{2} / \mathrm{sec}$ at $25^{\circ}$ for both carrier forms, calculations were performed for the expected oxygen flux based on this assumed diffusivity and the saturation curve for this system. It was found that the predicted fluxes of this model differed by only about $5 \%$ from those predicted by the unequal diffusivity model and that this method of calculation for the equilibrium model provides a good estimate of the expected oxygen fluxes even though the diffusion coefficients of the carrier forms are significantly different.

Based on the assumption that the binary diffusion coefficients of the two carrier forms are equal, comparison calculations were performed to predict the degree of facilitation expected at the temperature considered in this study. Typical results are presented in Table I.

\section{TABLE I}

COMPARISON OF THEORETICAL PREDICTIONS WITH EXPERIMENTAL DATA

$C_{0}=0.02 \mathrm{M} ; P_{\mathrm{O}_{2}}=\mathrm{I}_{5} .00$ inches $\mathrm{Hg} ; A_{0}=15.5 \mathrm{~cm}^{2} ; L=0.0 \mathrm{I}_{4} \mathrm{~cm}$.

\begin{tabular}{|c|c|c|c|}
\hline \multirow[b]{2}{*}{ Temp. } & \multicolumn{3}{|c|}{ Facilitation $\left(\mathrm{mm}^{3} / \mathrm{min} 25^{\circ}, \mathrm{I} \mathrm{atm}\right)$} \\
\hline & $\begin{array}{l}\text { Equilibrium } \\
\text { model }\end{array}$ & $\begin{array}{l}\text { Nonequilibrium } \\
\text { model }\end{array}$ & Measured \\
\hline $\begin{array}{l}12^{\circ} \\
18^{\circ} \\
25^{\circ}\end{array}$ & $\begin{array}{l}31.8 \\
37.2 \\
42.8\end{array}$ & $\frac{-}{9 . I}$ & $\begin{array}{l}4 \cdot 3 \\
6.0 \\
8.8\end{array}$ \\
\hline
\end{tabular}

SUMMARY AND CONCLUSIONS

Facilitated diffusion in the cobaltodihistidine-oxygen system behaved, under the experimental conditions imposed in this study, as a nonequilibrium diffusion plus 
chemical reaction system. Other features of this system which make it a general model for the study of facilitated diffusion are: (I) the stoichiometry of the reaction is not simply-I mole of carrier plus I mole of permeant giving I mole of carrier complex; (2) the carrier-permeant reaction takes place in several steps; (3) the diffusion coefficients of all species are unequal. Although, the mechanism of carrier transport in natural membranes by molecular diffusion has not been confirmed, this study shows the types of behavior that might be expected for such a mechanism. Numerical methods were developed for predicting facilitated fluxes for simple carrier systems of complex stoichiometry, slow or fast reaction rates and nonequal diffusivities of the carrier species.

Peculiarities which arose in this system, such as the solubility limit of one of the carrier species and irreversible reaction at high temperature, serve as warnings to the complexities that may remain hidden in biological transport processes.

Of particular significance is the fact that, even for a relatively simple transport system as studied here, a large amount of physical data in the form of diffusion and kinetic constants were required to unequivocally evaluate the transport mechanism. This is especially apparent in view of the experimentally determined oxygen flux curves and effect of a membrane thickness, which could have been interpreted in terms of a equilibrium facilitation model and a much lower diffusivity for the carrier species, had this data not been independently determined. The possibility of obtaining as good data for biological transport systems is somewhat less likely, and therefore the road to proving biological transport mechanisms somewhat more precarious.

In view of the experimental results of this study, it is felt that the primary contribution of this work is to provide an engineering study of a transport phenomenon which is of physiological importance. In view of the similarity between certain physiological problems and problems of engineering interest, the results of such a study as this are often of value in both areas of research. It is hoped that this investigation offers an example of one such problem of common interest.

\section{ACKNOWLEDGMENT}

This work was supported in part by the National Institute of Health, Grant No. GMr3402 and GM-I5I52.

\section{REFERENCES}

I W. Wilbrandt and T. Rosenberg, Exptl. Cell Res., 9 (1955) 49.

2 J. A. JAcQuez, Biochim. Biophys. Acta, 79 (1964) 318.

3 R. Blumenthal and A. Katchalsky, Biochim. Biophys. Acta, I 73 (1969) 357.

4 J. Wyman, $J$. Biol. Chem., 24I (I966) II 5.

5 R. C. LaForce, Trans. Faraday Soc., 58 (1962) I 458.

6 H. Kutchai, J. A. Jaceuez and F. J. Mather, Biophys. J., ro (1970) 38.

7 S. K. Friedlander and K. H. Keller, Chem. Eng. Sci., 20 (I965) I 2 I.

8 E. A. Hemmingsen, Comp. Biochem. Physiol., ro (1963) 239.

9 E. A. Hemmingsen, Science, I35 (I962) 733.

Io E. A. Hemmingsen ANd P. F. Scholander, Science, I 32 (I960) I379.

i 1 P. F. Scholander, Science, I3I (I960) 585.

I2 T. R. Strin, Augmented Diffusion of Oxygen, Ph. D. Thesis, University of Minnesota, 1968.

I3 J. B. WittenBerg, J. Biol. Chem., 24 I (Ig66) I04. 
I4 W. J. WARD and W. L. RobB, Science, I56 (I967) I48I.

I5 T. ENNS, Science, I55 (1967) 44.

I6 I. S. Longmuir, R. E. Forster and Chi-YuAN Woo, Nature, 209 (Ig66) 393.

I 7 R. J. BASSETT, Fractionation of Oxygen-Nitrogen Mixtures by Non-Equilibrium Facilitated Diffusion in Liquid Membranes, Ph. D. Thesis, University of Michigan, I969.

I 8 J. Z. Hearon, D. Burk and A. L. Schade, J. Natl. Cancer Inst., 9 (I949) 337.

19 J. Simplicio and R. G. Wilkins, J. Am. Chem. Soc., 89 (1967) 6092.

20 K. A. Fraser, H. A. Long and M. M. Harding, Chem. Commun. (1965) 334.

2 I C. C. McDonald and W. D. Phillips, J. Am. Chem. Soc., 85 (rg63) 3736.

22 Y. Sano and H. TANabe, J. Inorg. Nucl. Chem., 25 (I963) iI.

23 L. Michaelis, Arch. Biochem., I 4 (1967) I7.

24 P. Silverstroni, Ricerca Sci., 29 (I959) 3 OI.

25 L. J. Zompa, C. S. Sokol and C. H. Brubaker, Chem. Commun., (1967) 7 or.

26 M. T. BECK, Naturwissenschaften, 45 (1958) I62.

27 J. Csaszar, L. KISS AND M. T. BECK, Naturwissenschaften, 45 (I958) 210.

28 K. H. Keller and S. K. Friedlander, J. Gen. Physiol., 49 (I966) 663.

29 J. D. Goddard, J. S. Schultz ANd R. J. BAsSett, Chem. Eng. Sci., 25 (1970) 665.

30 D. R. Olander, Am. Inst. Chem. Eng. J., 6 (1960) 233.

3 I L. F. Nims, $A m$. J. Physiol., 20I (I96I) 987.

Biochim. Biophys. Acta, 2 II (1970) 194-21 5 